\title{
Open Source Is Changing the Way Work Gets Done
}

\author{
Stormy Peters \\ GNOME Foundation, USA
}

\begin{abstract}
Open source software is changing not only the way the software industry works, but also the way work gets done. In the open source software model, individuals and companies collaborate together to produce software. They learn new ways of getting work done that are based on meritocracy and little management. In addition, they learn ways of communication that work well across large groups and virtual environments. These new ways of communicating and getting work done are changing the nature of work across all industries, not just the software industry, industries like mobile technology providers and medical equipment. Come learn how the open source software model is changing the way individuals and companies work and collaborate.
\end{abstract}

